\title{
Stronger bonds between 25-hydroxyvitamin D $1 \alpha$-hydroxylase and pseudovitamin D-deficiency rickets
}

\author{
Jens P Berg \\ Hormone Laboratory, Aker University Hospital, Trondheimsveien 235, N-0514 Oslo, Norway
}

The D vitamins (cholecalciferols) are 'pre-pro-hormones' which become metabolically active after a sequence of hydroxylations $(1,2)$. Ergocalciferol (vitamin $\mathrm{D}_{2}$ ) is derived from plants, and cholecalciferol (vitamin $\mathrm{D}_{3}$ ) is produced in humans and animals. Vitamin D refers to either or both compounds. Three principal enzymes are involved in the activation or inactivation of vitamin $\mathrm{D}$, with respect to the vitamin D receptor, by hydroxylating carbon-25 (vitamin D 25-hydroxylase), carbon-1 in the $\alpha$-position (25-hydroxyvitamin D $1 \alpha$-hydroxylase), or carbon-24 (25-hydroxyvitamin D 24-hydroxylase). The hydroxylases belong to a family of enzymes known as cytochrome P450 mixed function monooxygenase (3). Three distinct parts of the enzymes, ferredoxin reductase, ferredoxin, and cytochrome P450, make an electron transport chain that ends in a heme prosthetic group bound to the cytochrome P450 subunit. Reduction of the iron ion attached to the heme molecule enables the enzymes to carry out the hydroxylation reactions.

Vitamin D is initially hydroxylated in the liver by vitamin D 25-hydroxylase. The activity of this hydroxylase is not influenced by calcium or phosphate homeostasis. In renal tubular cells, 25-hydroxyvitamin $\mathrm{D}$ is either converted to $1 \alpha, 25$-dihydroxyvitamin $\mathrm{D}$, which is the most potent naturally occurring vitamin $\mathrm{D}$ metabolite, or inactivated to 24,25-dihydroxyvitamin $\mathrm{D}$ by the enzymes 25 -hydroxyvitamin D $1 \alpha$-hydroxylase or 24-hydroxylase respectively. These two enzymatic systems respond to many of the same regulators, but in opposite directions. Parathyroid hormone (PTH) is the most important stimulator of $1 \alpha$-hydroxylase activity, which is also stimulated by phosphate depletion, oestrogens, prolactin, growth hormone, insulin, and calcitonin. The product of the enzymatic reaction, $1 \alpha, 25$-dihydroxyvitamin $\mathrm{D}$, attenuates enzyme activity via its receptor $(1,2)$.

Both rat 25-hydroxylase and 24-hydroxylase genes were cloned several years ago, whereas cloning of the $1 \alpha$-hydroxylase has been much more difficult due to its low level of expression $(4,5)$. Recently, two studies presented the cDNA sequences of the genes encoding mouse and rat $1 \alpha$-hydroxylase and the chromosomal location of the human counterpart of the gene. This represents a major break-through towards a genetic diagnosis of hereditary pseudovitamin D deficiency (vitamin D-dependent) rickets type I, a rare autosomal recessive disorder associated with defects in the $1 \alpha$-hydroxylase $(6,7)$.
In an elegantly designed study, Takeyama et al. (8) used kidney cells from mice lacking the vitamin D receptor in their approach to clone the $1 \alpha$-hydroxylase gene. These animals have abnormally high serum levels of $1 \alpha, 25$-dihydroxyvitamin $\mathrm{D}_{3}$, indicating a high $1 \alpha$-hydroxylase activity and high levels of the $1 \alpha$-hydroxylase mRNA. Renal cell mRNA from these animals was used to make a cDNA expression library in an eukaryotic cell line (COS-1 cells). The cells were also transfected with a vector encoding a fusion protein constructed with the ligand-binding domain of the vitamin D receptor and the yeast GAL4 DNA-binding domain. In addition, the cells were transfected with a reporter plasmid expressing the enzyme $\beta$-galactosidase in response to GAL4 activation. Cells transfected with the $1 \alpha$-hydroxylase gene from the cDNA library converted 25-hydroxyvitamin $\mathrm{D}_{3}$ added to the cell cultures to $1 \alpha, 25$-dihydroxyvitamin $\mathrm{D}_{3}$, which subsequently activated the fusion protein and the expression of $\beta$-galactosidase. Cells expressing this enzyme were stained when incubated with X-Gal. Stained cells were harvested, and their cDNA originating from the renal cell library was amplified by PCR. The PCR products were purified, subcloned into a new vector and sequenced.

The cDNA sequences indicated that the mouse $1 \alpha$ hydroxylase has an open reading frame consisting of 507 amino acids and a molecular mass of $55 \mathrm{kDa}$. The protein has a mitochondrial target signal and is homologous to members of the cytochrome P450 family of enzymes. It has a putative sterol-binding domain and a heme-binding domain with between 60 and $93 \%$ sequence similarities to rat vitamin D 25-hydroxylase and mouse 25-hydroxyvitamin D 24-hydroxylase. Subsequent studies confirmed that the enzyme encoded by the cloned cDNA could convert 25-hydroxyvitamin $\mathrm{D}_{3}$ to $1 \alpha, 25$-dihydroxyvitamin $\mathrm{D}_{3}$.

Expression of the gene was limited to the kidneys in normal mice and was 50-fold higher in 7-week-old vitamin $\mathrm{D}$ receptor deficient mice. The transcript was not detected in cells and tissues previously reported to have $1 \alpha$-hydroxylase activity, such as macrophages and placenta. Interestingly, the cytochrome P450 enzyme CYP27 has also been shown to hydroxylate 25hydroxyvitamin $\mathrm{D}_{3}$ in the $1 \alpha$-position (9). Expression of the $1 \alpha$-hydroxylase gene was reduced in normal mice

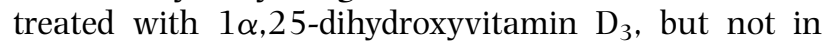
vitamin $\mathrm{D}$ receptor deficient mice, indicating that the 
liganded vitamin D receptor down-regulates the level of $1 \alpha$-hydroxylase.

St-Arnaud et al. (10) used a different approach and cloned the gene encoding $1 \alpha$-hydroxylase from a cDNA library based on kidney mRNA from vitamin D deficient rats. Based on the assumption that the $1 \alpha$-hydroxylase and 24-hydroxylase genes have similar sequences in the heme-binding domain, the library was screened with low stringency with a DNA probe encompassing this region of the rat 24-hydroxylase cDNA. The cDNAs obtained indicated an open reading frame of the rat $1 \alpha$ hydroxylase of $1503 \mathrm{bp}$ encoding a 501 amino acid protein of $55 \mathrm{kDa}$. Expression of the gene was upregulated in kidneys from mice treated with PTH and attenuated by treatment with 1,25-dihydroxyvitamin $\mathrm{D}_{3}$.

A human genomic clone containing the $1 \alpha$-hydroxylase gene was obtained using the rat cDNA as a probe. By fluorescent in situ hybridisation the labelled clone indicated that the human $1 \alpha$-hydroxylase gene is located on the long arm of chromosome 12, region q13.1-q13.3. The locus for pseudovitamin D-deficiency rickets has been shown to be in the interval $12 \mathrm{q} 13-\mathrm{q} 14$ (11), which strongly suggests that mutations in the $1 \alpha$-hydroxylase gene are responsible for this phenotype. The search for mutations that may link the gene with the disease has already started.

\section{References}

1 Henry HL, Dutta C, Cunningham N, Blanchard R, Penny R, Tang C et al. The cellular and molecular regulation of $1,25-(\mathrm{OH})_{2} \mathrm{D}_{3}$ production. Journal of Steroid Biochemistry and Molecular Biology $199241401-407$

2 Bouillon R, Okamura WH \& Norman AW. Structure-function relationships in the vitamin D endocrine system. Endocrine Reviews $199516200-257$.

3 Degtyarenko K. Structural domains of P450-containing monooxygenase systems. Protein Engineering 19958 737-747.

4 Usui E, Noshiro M \& Okuda K. Molecular cloning of cDNA for vitamin $\mathrm{D}_{3}$ 25-hydroxylase from rat liver mitochondria. FEBS Letters 1990262 135-138.
5 Ohyama Y, Noshiro M \& Okuda K. Cloning and expression of cDNA encoding 25-hydroxyvitamin $\mathrm{D}_{3}$ 24-hydroxylase. FEBS Letters 1991273 195-198.

6 Prader A, Illig R \& Heierli E. Eine besondere Form der primären Vitamin D resistenten Rachitis mit Hypocalcemie und autosomal dominanten Erbgang: Die hereditäre Pseudomangelrachitis. Helvetica Paediatrica Acta 196116 452-468.

7 Fraser D, Kooh S, Kind P, Holick M, Tanaka Y \& De Luca H. Pathogenesis of hereditary vitamin D-dependent rickets. New England Journal of Medicine 1973289 817-822.

8 Takeyama K-I, Kitanaka S, Sato T, Kobori M, Yanagisawa J \& Kato S. 25-Hydroxyvitamin $\mathrm{D}_{3} 1 \alpha$-hydroxylase and vitamin D synthesis. Science 1997277 1827-1830.

9 Axén E, Postlind H, Sjöberg H \& Wikvall K. Liver mitochondrial cytochrome-P450 CYP2 7 and recombinantly expressed human CYP27 catalyze 1-alpha-hydroxylation of 25-hydroxyvitamin $\mathrm{D}_{3}$. Proceedings of the National Academy of Sciences of the USA 199491 10014-10018.

10 St-Arnaud R, Messerlian S, Moir J, Omdahl J \& Glorieux F. The 25hydroxyvitamin D 1-alpha-hydroxylase gene maps to the pseudovitamin D-deficiency rickets (PDDR) disease locus. Journal of Bone and Mineral Research 199712 1552-1559.

11 Labuda M, Labuda D, Korab-Laskowska M, Cole D, Zietkiewicz E, Weissenbach J et al. Linkage disequilibrium analysis in young populations: Pseudo-vitamin D-deficiency rickets and the founder effect in French Canadians. American Journal of Human Genetics $199659633-643$.

\section{Note added in proof}

The rat $1 \alpha$-hydroxylase gene sequence was recently also reported by Shinki et al. (Proceedings of the National Academy of Sciences of the USA 199794 1292012925). Monkawa et al. (Biochemical and Biophysical Research Communications 1997239 527-533) cloned the human $1 \alpha$-hydroxylase gene and showed that it consists of nine exons and is present as a single copy. Finally, Fu et al. (Molecular Endocrinology 199711 1961-1970) also cloned the human gene and established the molecular basis of pseudovitamin D-deficiency rickets by demonstrating that a patient with the disease was a compound heterozygote for two null mutations in the $1 \alpha$-hydroxylase gene. 